\title{
PENGARUH SERVICE RECOVERY TERHADAP CUSTOMER SATISFACTION PADA HOTEL ROYAL JEMBER
}

\author{
Luccy Avrindy Ragilia Putri ${ }^{1}$ \\ Email: laragiliaputi13@yahoo.com
}

\section{Bambang Irawan ${ }^{2}$}

Elok Sri Utami ${ }^{3}$

\begin{abstract}
This article aims to determine the effect of service recovery consisting of procedural justice, interactional justice and distributive justice on customer satisfaction in guests Hotel Royal Jember. Methods of data collection is done by distributing questionnaires to 104 respondents who are guests Hotel Royal Jember with the following criteria must be at least 17 years because they have had the income and able to use the services of the hotel and was the guest of Hotel Royal Jember ever experienced complaint when using the services of Hotel Royal Jember, The data used in this study are primary data and secondary data. The data analysis method used is logistic regression analysis. The results showed that the variables used are service recovery consisting of procedural justice, interactional justice and distributive justice effect on customer satisfaction in guests Hotel Royal Jember.
\end{abstract}

Keywords: Distributive Justice, Interactional Justice, Procedural Justice, Customer Satisfaction.

\section{PENDAHULUAN}

Perkembangan bisnis yang semakin luas dan persaingan yang semakin ketat menjadi ancaman dan juga peluang bagi pelaku bisnis yang sudah maupun akan membangun bisnisnya. Salah satunya kota Jember yang saat ini telah dinobatkan sebagai Kota Karnaval pertama di Indonesia. Penempatan Jember sebagai Kota Karnaval pertama di indonesia ini harus dimanfaatkan dengan baik oleh para pelaku usaha untuk terus berinovasi mengikuti perkembangan zaman agar bisnisnya tetap berjalan dengan baik dan mencapai target yang diinginkan. JFC atau Jember Fashion

\footnotetext{
${ }^{1}$ Corresponding author: Jurusan Manajemen, Fakultas Ekonomi dan Bisnis, Universitas Jember, Jalan Kalimantan No. 37, Kampus Tegalboto, Kecamatan Sumbersari, Jember, 68121, Jawa Timur, Indonesia.

${ }^{2,3}$ Jurusan Manajemen, Fakultas Ekonomi dan Bisnis, Universitas Jember, Jalan Kalimantan No. 37, Kampus Tegalboto, Kecamatan Sumbersari, Jember, 68121, Jawa Timur, Indonesia.
} 
Carnaval merupakan salah satu daya tarik bagi turis asing maupun domestik untuk bekunjung ke Jember. Hal ini tentunya sangat menguntungkan bagi bisnis pariwisata seperti Hotel. Hotel termasuk sarana pokok kepariwisataan (main tourism superstrucktures) yang berarti kehidupannya tergantung pada jumlah wisatawan yang datang. Semakin tinggi jumlah wisatawan yang datang maka tingkat permintaan kamar yang disediakan semakin bertambah dan ini akan meningkatkan profit perusahaan. Peran hotel dalam industri pariwisata memang sangat penting. Hotel juga telah membantu menciptakan lapangan pekerjaan, membantu perkembangan industri-industri kecil, terjaganya kelestarian alam serta kebudayaan destinasi pariwisata, dan tentu saja meningkatkan devisa negara.

Bisnis hotel di Indonesia cukup potensial mengingat Indonesia memiliki destinasi dan keindahan alam serta keragaman budayanya yang unik. Potensi inilah yang menjadi modal utama dalam industri pariwisata agar kelestariannya dapat terus terjaga. Bisa dikatakan bahwa perkembangan bisnis perhotelan di Indonesia sendiri sudah mengalami banyak peningkatan yang cukup signifikan. Hal ini dapat dilihat dari meningkatnya industri pariwisata dan jumlah kunjungan wisatawan asing ke Indonesia yang semakin meningkat. Akibatnya banyak investor yang membangun hotel berjejaring di berbagai wilayah di Indonesia. Berbagai usaha dilakukan tidak hanya tampilan luar hotel yang unik, fasilitas yang lengkap, tempat yang nyaman hingga tatanan kamar yang menarik tetapi juga pelayanan yangbaik diberikan dengan harapan memenuhi kebutuhan dan kepuasan pengunjung yang datang.

Seiring berjalannya waktu, hotel sebagai industri perdagangan yang bergerak di bidang jasa tidak hanya menyediakan tempat menginap saja tetapi juga menyediakan berbagai fasilitas-fasilitas umum lainnya seperti meeting room, swimming pool, restaurant, convention hall, karaoke, bahkan jasa pijat juga disediakan di hotel. Hal ini sangat membantu pengunjung agar lebih mudah untuk melakukan aktivitas tanpa harus mengurangi rasa nyaman selama menginap dihotel tersebut. Tentunya hal ini akan berdampak pada kepuasan dan kepercayaan pelanggan untuk melakukan pemesanan kembali. Waktu beroperasi hotel yang berlangsung selama 24 jam nonstop setiap hari tanpa adanya hari libur yang bertujuan agar dapat melayanai tamu hotel yang akan menggunakan jasa hotel. Pelayanan yang diberikan harus memenuhi standar pelayanan sehingga pengunjung merasa puas. Kunci sukses bagi setiap perusahaan adalah bersikap proaktif dalam menekan setiap kemungkinan terjadinya kegagalan jasa dan membekali karyawannya dengan serangkaian alat pemulihan (recovery) yang efektif guna memperbaiki kegagalan yang terjadi dalam memuaskan pelanggannya Yuliana $(2012,39)$. Namun dalam memberikan pelayanan yang baik kepada pengunjung terkadang terjadi service failure atau kegagalan dalam pelayanannya. Untuk mengatasi dampak negatif dari kegagalan pelayanan tersebut maka diperlukan pemulihan pelayanan atau service recovery.

Andreassen (2000) menyatakan service recovery merupakan upaya sistematis yang dilakukan oleh perusahaan setelah kegagalan jasa untuk memperbaiki suatu masalah dan mempertahankan kehendak baik bagi pelanggan. Menurut Kau dan Loh (2006) service recovery secara umum dapat diwujudkan dengan tiga cara pokok yaitu: procedural justice, interactional justice, distributive justice. Menurut Barnes (2003) procedural justice merupakan atribut yang memfokuskan pada keadilan yang diterima oleh konsumen ketika mengajukan komplain sesuai dengan peraturan dan kebijakan yang telah ditetapkan perusahaan, dengan ini maka perusahaan dapat 
meningkatkan kepuasan melalui recovery dengan terlibat dalam kegiatan yang meningkatkan persepsi pelanggan mengenai procedural justice. Menurut Tjiptono (2014), interactional justice merupakan atribut yang memfokuskan pada perlakuan interpersonal yang diterima pelanggan dari penyedia jasa atau perusahaan. Menurut Kau dan Loh (2006) distributive justice merupakan justice/fairness yang dipersepsikan oleh customer sebagai hasil dari complain. Keluhan harus dikelola secara sistematis untuk meneliti sebuah permasalahan pelayanan dan menyelesaikannya sebagai upaya untuk mencapai dan mempertahankan kepuasan pelanggan. Menurut Yunri (2014) ketika seorang konsumen mengajukan komplain pada penyedia jasa hotel maka konsumen tersebut akan mempunyai ekspektasi lebih akan hasil yang diterima setelah pengajuan komplain dilakukan. Hasil inilah yang akan menentukan tingkat kepuasan konsumen dalam menerima pemulihan jasa yang dilakukan oleh perusahaan penyedia jasa. Oleh karena itu, prosedur pemulihan jasa sangat penting dimiliki perusahaan untuk mencapai kepuasan dan loyalitas pelanggan Supriyanto (2006).

Menurut Tjiptono (2014) komitmen perusahaan sangat penting dalam mendengar dan merespon suara konsumen. Pemulihan pelayanan atau service recovery ini sangat membantu perusahaan dalam mengembalikan kepuasan dan kepercayaan pengunjung terhadap layanan yang mereka berikan. Kepuasan pelanggan atau customer satisfaction akan timbul pada saat konsumen telah menggunakan layanan atau jasa yang diberikan oleh perusahaan. Kepuasan pelanggan merupakan salah satu tujuan utama perusahaan dalam melakukan bisnisnya (Ardito 1996; McDougall dan Levesque 2000). Pengunjung yang puas akan merasa mendapatkan value dari jasa yang telah diberikan. Kepuasan pelanggan terhadap service recovery yang dilakukan oleh perusahaan atau penyedia jasa bergantung pada bagaimana persepsi keadilan yang dirasakan oleh pelanggan ketika keluhan ditangani. Dengan strategi service recovery yang efektif akan membantu dalam memecahkan permasalahan dan mampu menangani kekecewaan pengunjung terhadap pelayanan yang diberikan oleh pihak hotel, sehingga strategi service recovery yang diberikan sangat penting dimiliki oleh pihak hotel untuk dapat mencapai kepuasan pelanggan.

Pertumbuhan bisnis Hotel di Kabupaten Jember Jawa Timur terus meningtkat seiring dengan banyaknya sejumlah investor yang mendirikan hotel baru di wilayah Jember, hal ini dikarenakan Jember memiliki pasar yang potensial sehingga para pengusaha tertarik untuk menanamkan investasinya dengan membuka hotel baru (Solichah 2018). Salah satunya Hotel Royal Jember sebagai salah satu hotel bintang tiga yang terletak di pusat kota dekat area kampus tepatnya di Jl. Karimata 50 Kav.2. Letak Hotel Royal sangat strategis dan mudah dijangkau oleh wisatawan yang berlibur di Jember. Hotel Royal tidak jauh dari Universitas Muhammadiyah Jember dan terletak di pusat kota dengan 4 lantai yang dirancang dengan gaya modern, kontemporer dan unik. Tipe kamar yang disediakan juga bervariasi mulai dari Gold Standart Room, Platinum Superior, Sapphire Deluxe, Royal Diamond Suite. Royal Hotel juga memiliki sebuah restaurant yang menyediakan makanan khas Indonesia maupun Internasional. Dengan adanya program tahunan kunjungan wisata di jember semakin menjadikan kota Jember sebagai tujuan utama objek wisata. 
Tabel 1. Data Kamar di Pesan Hotel Royal Jember

\begin{tabular}{cc}
\hline Bulan & Jumlah Kamar yang di Pesan \\
\hline Januari & 1.987 \\
Februari & 1.939 \\
Maret & 1.732 \\
April & 1.897 \\
Mei & 948 \\
Juni & 2.099 \\
\hline
\end{tabular}

Sumber: Hotel Royal Jember, 2019

Berdasarkan hasil prariset yang ditunjukan pada Tabel 1 dapat diketahui bahwa jumlah kamar yang dipesan pada hotel Royal pada bulan Januari 2019 sampai dengan bulan Juni 2019 mengalami fluktuasi namun cenderung mengingkat. Menurut Room Division Manager Hotel Royal Jember mengatakan bahwa tamu yang berkunjung dan menginap sebagian besar merupakan tamu yang pernah berkunjung dan menginap di Hotel Royal Jember. Namun, tidak semua pelayanan yang disuguhkan selalu mendapat respon positif dari pengunjung, ada pula pengunjung yang merasa tidak puas dengan pelayanan yang diberikan. Berdasarkan lembar guest comment Hotel Royal Jember, masih terdapat tamu yang mengeluhkan kurangnya pelayanan yang optimal seperti fasilitas WiFi yang lambat, air panas yang tidak stabil, menu makanan yang tersedia kurang bervariasi, kebocoran wastafel dan lampu baca yang tidak berfungsi. Selain berdasarkan lembar guest comment, tamu juga mengungkapkan keluhannya pada review tamu pada salah satu aplikasi pemesanan hotel Traveloka menunjukan terdapat beberapa keluhan tamu pada Hotel Royal selama Bulan Juni 2019. Keluhan yang diungkapkan tamu mengenai fasilitas hotel seperti AC mati, WiFi yang tidak dapat terkoneksi, lampu yang kurang terang, kasur yang berbunyi serta penyiram toilet bocor. Keluhan yang diungkapkan tamu mengenai kebersihan hotel seperti kasur yang kurang bersih, air yang berwarna kuning, lantai dan karpet yang kotor. Keluhan yang diungkapkan tamu mengenai pelayanan hotel seperti menu makanan yang kurang bervariasi, rasa makanan yang terlalu asin, serta tidak adanya room boy yang dapat membantu tamu membawa koper. Keluhan yang diungkapkan tamu mengenai pelayanan sopan yaitu resepcionist yang tidak ramah.

Rumusan masalah dalam penelitian ini adalah apakah variabel service recovery yang terdiri atas distributive justice, interactional justice dan procedural justice berpengaruh terhadap customer satisfaction pada Hotel Royal Jember?

Penelitian ini bertujuan untuk mengetahai dan menganalisis pengaruh variabel service recovery yang terdiri atas distributive justice, interactional justice dan procedural justice berpengaruh terhadap customer satisfaction pada Hotel Royal Jember.

\section{METODE PENELITIAN}

\subsection{Rancangan atau Desain Penelitian}

Penelitian ini termasuk ke dalam explanatory research (penelitian penjelasan), karena penelitian ini bertujuan untuk menjelaskan hubungan sebab akibat antara variabel independen yaitu procedural justice, interactional justice, distributive justice dan variabel dependen yaitu customer satisfaction. Penelitian ini bersifat kuantitatif dengan objek penelitian tamu pada Hotel Royal Jember. 


\subsection{Jenis dan Sumber Data}

Jenis data yang digunakan dalam penelitian ini adalah data kuantitatif. Sumber data yang digunakan dalam penelitian ini adalah sumber data primer dan sekunder. Sumber data primer berupa hasil jawaban dari pernyataan responden dan berupa karakteristik responden. Sedangkan sumber data sekunder berupa studi pustaka dari buku, jurnal dan internet.

\subsection{Populasi dan Sampel}

Populasi yang digunakan pada penelitian ini adalah semua tamu Hotel Royal Jember. Sanpel yang digunakan sebanyak 104 orang yang ditentukan dengan teknik purposive sampling yaitu penentuan sampel dengan kriteria antara lainberusia 17 tahun keatas dan merupakan tamu Hotel Royal Jember yang pernah mengalami keluhan saat menggunakan jasa Hotel Royal Jember

\subsection{Metode Analisis Data}

Metode analisis data yang digunakan dalam penelitian ini adalah analisis regresi logistik dengan menggunakan software SPSS versi 22.

\section{HASIL DAN PEMBAHASAN}

\subsection{Karakteristik Responden}

Responden dalam penelitian ini berjumlah 104 orang dengan klasifikasi karakteristik responden berdasarkan jenis kelamin, usia, profesi dan penghasilan.

Tabel 2. Karakteristik Responden

\begin{tabular}{|c|c|c|c|}
\hline \multicolumn{2}{|c|}{$\begin{array}{ll}\text { No } & \text { Keterangan } \\
\end{array}$} & Jumlah & Persentase $(\%)$ \\
\hline \multicolumn{4}{|c|}{ 1.Jenis Kelamin } \\
\hline & Laki-laki & 56 & 53,8 \\
\hline & Perempuan & 48 & 46,2 \\
\hline \multicolumn{2}{|r|}{ Total } & 104 & 100 \\
\hline \multicolumn{4}{|c|}{ 2.Usia } \\
\hline & $17-25$ Tahun & 28 & 26,9 \\
\hline & $26-35$ Tahun & 34 & 32,7 \\
\hline & $36-456$ Tahun & 29 & 27,9 \\
\hline & Lebih dari 45 Tahun & 13 & 12,5 \\
\hline \multicolumn{2}{|r|}{ Total } & 104 & 100 \\
\hline \multirow[t]{6}{*}{3.} & Profesi & & \\
\hline & Mahasiswa/Pelajar & 17 & 16,3 \\
\hline & Pegawai Negeri & 25 & 24,0 \\
\hline & Pegawai Swasta & 20 & 19,2 \\
\hline & Wiraswasta & 42 & 40,4 \\
\hline & Total & 104 & 100 \\
\hline \multirow[t]{6}{*}{4} & Penghasilan & & \\
\hline & $1-2$ Juta Rupiah & 17 & 16,3 \\
\hline & $2-3$ Juta Rupiah & 25 & 24,0 \\
\hline & Lebih dari 3 Juta Rupiah & 20 & 19,2 \\
\hline & Wiraswasta & 42 & 40,4 \\
\hline & Total & 104 & 100 \\
\hline
\end{tabular}

Sumber: Data Primer diolah, 2019 
Berdasarkan Tabel 2. dapat diketahui bahwa responden terbanyak merupakan responden berjenis kelamin laki-laki dengan jumlah 56 responden atau 53,8\%. Hal ini dikarenakan laki-laki lebih banyak melakukan beberapa aktivitas pekerjaan mereka seperti melakukan rapat dan pertemuan dengan patner kerja mereka dihotel. Namun, jumlah responden berjenis kelamin perempuan juga tidak jauh berbeda dengan jumlah pengunjung laki-laki. Berdasarkan karakteristik usia, responden terbanyak merupakan responden berusia antara 26 - 35 tahun dengan jumlah 34 responden atau $32,7 \%$. Hal ini dikarenakan pada usia 26 - 35 tahun merupakan usia produktif dan cenderung usia dimana seseorang sangat menyukai kegiatan travelling atau liburan ke luar kota sehingga hotel akan menjadi salah satu pilihan untuk mereka menginap beberapa hari saat melakukan liburan. Berdasarkan karakteristik profesi, responden terbanyak merupakan responden berprofesi sebagai wiraswasta dengan jumlah 42 responden atau 40,4\%. Hal ini dikarenakan seseorang dengan profesi sebagai wiraswasta memiliki banyak waktu luang dan sering melakukan liburan ke luar kota termasuk Jember sehingga banyak dari mereka menggunakan jasa hotel untuk menginap. Sedangkan berdasarkan karakteristik penghasilan, responden terbanyak merupakan responden dengan penghasilan lebih dari Rp 3.000 .000 dengan jumlah 53 responden atau 51.0\%. Hal ini dikarenakan seseorang yang menginap dihotel harus memiliki uang lebih dikarenakan biaya hotel saat ini cukup mahal dan menginap di hotel dapat dikatakan kebutuhan tersier bukan termasuk kebutuhan-kebutuhan primer.

\subsection{Analisis Regresi Logistik}

Setelah dilakukan uji validitas yang menghasilkan semua data valid dan uji reliabilitas yang menghasilkan data reliable, maka dilanjutkan dengan analisis regresi logistik. Ringkasan hasil analisis regresi logistik dapat dilihat pada Tabel 3.

Tabel 3. Hasil Analisis Regresi Logistik

\begin{tabular}{lcc}
\hline & B & Sig \\
\hline Procedural Justice (X1) & 0,883 & 0,037 \\
Interactional Justice (X2) & $1,2010,025$ \\
Distributive Justice (X3) & $3,3160,028$ \\
Constant & $-29,7620,022$ \\
\hline
\end{tabular}

Sumber: Output SPSS diolah, 2019

Berdasarkan Tabel 43 dihasilkan persamaan regresi logistik sebagai berikut: $\mathrm{Ln}=(\mathrm{P} / 1-\mathrm{P})=-29,762+0,883 \mathrm{X} 1+1,201 \mathrm{X} 2+3,316+\mathrm{e}$

Persamaan 1. Hasil Analisis Regresi Logistik

\subsection{Menilai Model Fit}

Menilai model fit dilakukan untuk menguji variabel yang berpengaruh dari masing-masing variabel independen dalam penelitian ini yaitu procedural justice (X1), interactional justice (X2) dan procedural justice (X3) terhadap variabel dependen yaitu customer satisfaction (Y). Untuk menilai model fit dilakukan tiga penilaian yang mencangkup tahap-tahap berikut : 
a. Menganalisa Model fit

Berdasarkan hasil analisis dengan regresi logistik diketahui bahwa hasil uji ketepatan keseluruhan model pada block number $=0$ menunjukan nilai pada $-2 \mathrm{Log}$ Likelihood sebesar 85,815. Setelah seluruh variabel independen (block number $=1$ ) dimasukan ke dalam model -2Log Likelihood maka terjadi perubahan nilai sebesar 15,854. Hal ini menunjukan bahwa terjadi penurunan -2 Log Likelihood sebesar 69,961 sehingga dapat diartikan bahwa penambahan variabel bebas kedalam model dapat memperbaiki model fit serta menunjukan model lebih baik sehingga model persamaan regresi logistik tersebut fit dengan data.

b. Menganalisa Uji Hosmer and Lemeshow

Berdasarkan hasil analisis dengan regresi logistik diketahui bahwa nilai signifikansi pada uji Hosmer and Lemeshow menunjukan nilai sebesar 1,000 yang berarti lebih besar dari 0,05 sehingga dapat diartikan bahwa model persamaan yang terbentuk dinyatakan layak dan boleh diintepretasikan.

c. Menganalisa nilai Negelkerke R-Square

Berdasarkan hasil analisis dengan regresi logistik diketahui bahwa nilai Negelkerke R-Square menunjukan nilai sebesar 0,872 hal ini menunjukan terdapat indikasi bahwa variabel cutomer satisfaction (Y) yang bisa dijelaskan oleh variabel procedural justice (X1), interactional justice (X2) dan distributive justice (X3) adalah sebesar $87,2 \%$ sedangkan sisanya sebesar 13,8\% dijelaskan oleh variabel lain yang tidak dimasukan dalam penelitian ini.

d. Hasil ketiga penilaian model fit menunjukan bahwa model persamaan regresi logistikbersifat fit atau cocok dengan data. Dengan kata lain dapat dinyatakan bahwa penambahan variabel bebas yang terdiri dari procedural justice, interactional justice dan distributive justice pada customer satisfaction ke dalam model sehingga memperbaiki model fit.

\subsection{Uji Hipotesis}

Kemampuan variabel bebas dalam memprediksi variabel terikat dapat dilihat dari tingkat signifikansi uji wald masing-masing variabel. Apabila tingkat signifikansi > 0,05 maka variabel bebas tidak memiliki kemampuan mempengaruhi variabel terikat. Sebaliknya apabila tingkat signifikansi $<0,05$ maka variabel bebas memiliki kemampuan mempengaruhi variabel terikat. Ringkasan hasil uji wald dapat ditunjukan pada Tabel 5 berikut:

Tabel 4. Hasil Uji Wald

\begin{tabular}{lcc}
\hline Variabel & Sig & Keterangan \\
\hline Procedural Justice (X1) & 0,037 & H0 ditolak \\
Interactional Justice (X2) & 0,025 & H0 ditolak \\
Distributive Justice (X3) & 0,028 & H0 ditolak \\
\hline
\end{tabular}

Sumber: Ouput SPSS diolah, 2019

Berdasarkan Tabel 4. variabel procedural justice (X1), interactional justice (X2) dan procedural justice (X3) berpengaruh signifikan terhadap customer satisfaction pada tingkat $\alpha=5 \%$. Berikut penjelasan dari setiap variabel uji hipotesis:

\section{a. Hasil Uji Regresi Logistik Variabel Procedural Justice}

Hasil uji hipotesis dengan menggunakan uji wald menunjukan bahwa procedural justice memiliki nilai signifikansi 0,037 yang lebih kecil dari 0,05 hal ini berarti 
menerima hipotesis pertama, artinya procedural justice cenderung mempengaruhi secara signifikan terhadap customer satisfaction pada hotel Royal Jember.

\section{b. Hasil Uji Regresi Logistik Variabel Interactional Justice}

Hasil uji hipotesis dengan menggunakan uji wald menunjukan bahwa interactional justice memiliki nilai signifikansi 0,025 yang lebih kecil dari 0,05 hal ini berarti menerima hipotesis kedua, artinya interactional justice cenderung mempengaruhi secara signifikan terhadap customer satisfaction pada hotel Royal Jember.

\section{c. Hasil Uji Regresi Logistik Variabel Distributive Justice}

Hasil uji hipotesis dengan menggunakan uji wald menunjukan bahwa distributive justice memiliki nilai signifikansi 0,028 yang lebih kecil dari 0,05 hal ini berarti menerima hipotesis ketiga, artinya distributive justice cenderung mempengaruhi secara signifikan terhadap customer satisfaction pada hotel Royal Jember.

\subsection{Pengaruh Procedural Justice terhadap Customer Satisfaction}

Procedural justice cenderung mempengaruhi customer satisfaction dibuktikan dengan hasil uji wald yang menunjukan nilai signifikansi sebesar 0,037 yang lebih kecil dari 0,05. Hasil pengujian ini didukung dengan hasil deskripsi terhadap variabel procedural justice yang menunjukan bahwa responden terbanyak menjawab sangat setuju dan setuju yang mengindikasikan bahwa mayoritas responden berpendapat positif mengenai procedural justice yang dilakukan pihak hotel Royal Jember, artinya bahwa para tamu berpersepsi telah mendapat perlakukan yang seharusnya diterima ketika mengajukan komplain terhadap pihak hotel Royal Jember dan menciptakan customer satisfaction dibenak para tamu hotel.

Penelitian yang langsung dilakukan di Hotel Royal Jember serta hasil penyebaran kuesioner mengindikasikan bahwa procedural justice yang dilakukan oleh pihak pengelola hotel dalam melayani komplainn tamu sudah berjalan dengan baik yaitu pihak hotel bersikap adil kepada seluruh tamu untuk menanggapi komplain yang diajukan. Pengelola hotel tidak melihat batasan usia, jenis kelamin, jabatan ataupun jumlah penghasilan yang dimiiki oleh tamu tersebut guna mendapatkan penanganan atas komplain yang diajukan. Hal ini merupakan salah satu kebijakan pihak hotel untuk menciptakan kenyamanan para tamu agar tercipta rasa puas dan timbul keinginan untuk menginap kembali di Hotel Royal Jember. Ketika tamu melaporkan terjadinya kegagalan layanan dan pihak tamu melaporkan pada pihak hotel, proses yang dilalui mulai dari melaporkan sampaidengan masalah yang terjadi ditangani dengan baik dan cepat oleh pihak hotel Royal. Selain itu para karyawan juga dituntut untuk tanggap dan cepat sehingga para tamu tidak kesulitan mengadukan komplainnya serta hasil yang diperoleh sesuai dengan ekspektasi atau harapan para tamu.

\subsection{Pengaruh Interactional Justice terhadap Customer Satisfaction}

Interactional justice cenderung mempengaruhi customer satisfaction dibuktikan dengan hasil uji wald yang menunjukan nilai signifikansi sebesar 0,025 yang lebih kecil dari 0,05. Hasil pengujian ini didukung dengan hasil deskripsi terhadap variabel interactional justice yang menunjukan bahwa responden terbanyak menjawab sangat setuju dan setuju yang mengindikasikan bahwa mayoritas responden berpendapat positif mengenai intercational justice yang dilakukan pihal 
hotel Royal Jember, artinya bahwa para tamu berpersepsi bahwa pihak hotel Royal Jember telah melakukan perlakuan berupa respon yang sama terhadap semua tamu yang mengajukan komplian kepada pihak hotel. Sehingga menciptakan customer satisfaction dibenak para tamu hotel.

Penelitian yang langsung dilakukan di Hotel Royal Jember serta hasil penyebaran kuesioner mengindikasikan bahwa interactional justice secara langsung mempengaruhi kepuasan pelanggan. Untuk mendapatkan kepuasan dari para tamu hotel, pihak pengelola Hotel Royal Jember selalu berupaya untuk memperhatikan faktor interaksi personal antara karyawan dengan tamu dalam proses penanganan komplain. Karyawan Hotel Royal Jember memiliki sikap yang baik serta rama kepada seluruh tamu yang telah menjadi standar operasional prosedur hotel. Karyawan harus mampu memberikan sikap seperti mengajukan permohonan maaf kepada tamu secara tulus saat terjadi kegagalan layanan dari pihak hotel serta berupaya menebus kesalahan dengan mengganti kerugian yang dirasakan oleh tamu, membayar ganti rugi dalam bentuk barang ataupun melakukan perubahan harga sesuai dengan kondisi yang ada. Hal tersebut menjadikan tamu yang merasa kecewa dengan kegagalan pelayanan pihak Hotel Royal Jember akan menjadi puas karena mendapatkan pelayanan atas komplain yang diajukan, sikap karyawan dalam menangani komplain tamu serta respon dari pihak pengelola Hotel Royal Jember.

\subsection{Pengaruh Distributive Justice terhadap Customer Satisfaction}

Distributive justice cenderung mempengaruhi customer satisfaction dibuktikan dengan hasil uji wald yang menunjukan nilai signifikansi sebesar 0,028 yang lebih kecil dari 0,05. Hasil pengujian ini didukung dengan hasil deskripsi terhadap variabel distributive justice yang menunjukan bahwa responden terbanyak menjawab sangat setuju dan setuju yang mengindikasikan bahwa mayoritas responden berpendapat positif mengenai distributive justice yang dilakukan pihal hotel Royal Jember, artinya bahwa para tamu berpersepsi bahwa pihak hotel Royal Jember telah berperilaku yang memfokuskan pada hasil dari penyelesaian layanan yang telah dilakukan pihak hotel sehingga menciptakan customer satisfaction dibenak para tamu hotel.

Penelitian yang langsung dilakukan di Hotel Royal Jember serta hasil penyebaran kuesioner mengindikasikan bahwa distributive justice yang dilakukan oleh pihak Hotel Royal Jember berkategori baik yang artinya tamu telah merasa puas dengan keadilan distribusi yang diberikan pihak hotel saat tamu melakukan komplain atas kegagalan layanan yang dirasakannya. Pihak tamu merasa senang karena hal pertama yaitu pihak hotel meminta maaf atas kesalahan layanan yang dirasakan oleh para tamu yang dianggap tidak sesuai dengan harapannya. Konsumen lebih menyetujui apabila pemulihan jasa dilakukan dengan cara pemberian kompesasi sesuai dengan kesalahan yang dilakukan oleh pihak hotel karena dengan adanya kompensasi maka kerugian materil atau non materil yang dirasakan oleh para tamu tergantikan dan tamu tersebut menjadi puas kembali atas sikap dan tindakan pihak hotel dalam menangani kegaglan layanan yang tidak sengaja dilakukan. 


\section{KESIMPULAN}

Berdasarkan analisis yang telah dilakukan dalam penelitian ini, maka dapat ditarik kesimpulan bahwa service recovery memiliki kecenderungan mempengaruhi customer satisfaction. Hal tersebut membuktikan bahwa service recovery yang telah diberikan oleh pihak Hotel Royal Jember saat para tamu mengalami keluhan seperti menangani masalah dengan cepat dan tepat, perilaku karyawan yang tetap memberikan pelayanan dengan baik dan ramah pada para tamu yang melakukan complain dan penanganan keluhan yang dilakukan oleh pihak Hotel Royal Jember telah bersifat adil bagi kedua belah pihak hotel telah mampu membuat tamu yang awalnya kecewa atas keluhannya menjadi menjadi puas karena merasa mendapatkan pelayanan yang sesuai harapannya.

\section{DAFTAR PUSTAKA}

Andreassen, T. W. 2000. Antecedents to satisfaction with service recovery. Europe Journal of Marketing 34 (1):156-175.

Ardito, E. 1996. Mengelola Nilai Konsumen. Forum Manajemen Prasetiya Mulya (64):10-17.

Barnes, A. 2003. How to Maintain the Trust: A Study in Banking Customer. London: The Expert Press.

Kau, A. K., dan E. W. Y. Loh. 2006. The effects of service recovery on consumer satisfaction: a comparison between complainants and non-complainants. Journal of Services Marketing 20 (2):101-111.

McDougall, G. H. G., dan T. J. Levesque. 2000. Customer Satisfaction With Services: Putting Perceived Value Into The Equation. Journal of Service Marketing 14 (5):392-410.

Solichah, Z. 2018. Hunian Hotel di Jember Terus Berkembang. https://jatim.antaranews.com/berita/246594/hunian-hotel-di-jember-terus-.

Supriyanto, E. B. 2006. Budaya Kerja Perbankan. Jakarta: Pustaka LP3ES. Tjiptono, F. 2014. Pemasaran Jasa. Malang: Bayu Media

Yuliana, R. 2012. Analisis Pengaruh Strategi Service Recovery yang Dilakukan Perbankan Terhadap Kepuasan Nasabah di Kota Semarang. Jurnal STIE Semarang 4 (2):39-52.

Yunri, I. K. 2014. Pengaruh Startegi Service Recovery terhadap kepuasan Nasabah. Skripsi. Purworejo: Universitas Muhammadiyah Purworejo. 